\title{
Chemical and Biological Investigations of Axonopus compressus (Sw.) P. Beauv.
}

\author{
F. M. Mustafizur Rahman ${ }^{1}$, S. M. Fuad Kabir ${ }^{1}$, Md. Nurnabi ${ }^{1}$, A. M. Sarwaruddin \\ Chowdhury ${ }^{1}$ and Md. Al Amin Sikder ${ }^{2}$ \\ ${ }^{1}$ Department of Applied Chemistry and Chemical Engineering, Faculty of Engineering and Technology \\ University of Dhaka, Dhaka-1000, Bangladesh \\ ${ }^{2}$ Phytochemical Research Laboratory, Department of Pharmaceutical Chemistry, Faculty of Pharmacy \\ University of Dhaka, Dhaka-1000, Bangladesh
}

The crude $n$-hexane (HX), chloroform (CF) and methanol (ME) extracts of Axonopus compressus (Family: Poaceae) were subjected to screenings for antioxidant, antibacterial \& antifungal activities and cytotoxic against brine shrimp nauplii. The crude extracts (HX, CF and ME) did not show any antimicrobial activities, whereas, two fractions F-1 and F-2 obtained from CF extract exhibited mild to moderate sensitivity against all the test microorganisms. On the other hand, in brine shrimp lethality bioassay the $\mathrm{LC}_{50}$ values of $0.323,1.88,2.11$ and $2.50 \mu \mathrm{g} / \mathrm{ml}$ for vincristine sulphate (Std.), HX, CF and ME extracts, respectively indicate the presence of potent bioactive compounds. At the same time, the antioxidant potential was evaluated by 1,1-diphenyl-2-picrylhydrazyl (DPPH) reagent using tert-butyl-1-hydroxytoluene (TBHT) and ascorbic acid as reference standards. Among the crude extracts, only CF extract displayed significant antioxidant activity with $\mathrm{IC}_{50}$ value of $48.0 \mu \mathrm{g} / \mathrm{ml}$. A compound was purified from the chloroform extract of $A$. compressus and it was identified as $\beta$-sitosterol on the basis of ${ }^{1} \mathrm{H}$ NMR spectroscopy as well as co-TLC with authentic sample.

A. compressus is usually a robust plant and stoloniferous. It has stouter culms and stolons, wider leaves and longer spikelets which are more acute. A. compressus has been reported for various ethnomedical uses such as haemorrhoids (Soladoye et al., 2010), antimalarial (Busia, 2007; Lowe, 1989) and antidiabetic (Ibeh et al., 2011) activities. It is also reported for digestible protein and high starch content (Gohl, 1975) and in Brazil, it is widely considered to be a useful feed to gain weight for zebu steers (Rocha et al., 1962). A study showed that this herb can absorb trace metals and is recommended as remedies to the pollution problem of the environment (Ukpong et al., 2011). Previous phytochemical studies with $A$. compressus revealed it to contain alkaloid, flavonoids, polyphenols, saponin, inulin, cellulose and tannins (Ibeh et al., 2013). However, this species growing in Bangladesh has not been studied either for phytochemical or biological purposes.

The whole plant of $A$. compressus was collected from the Curzon Hall campus of Dhaka University, Bangladesh in 2008. The clean plant material was sun-dried for several days and then oven-dried for $24 \mathrm{hrs}$ at $40{ }^{\circ} \mathrm{C}$ and the dried materials were ground to a coarse powder.

About $100 \mathrm{gm}$ of the coarse powder of the whole plant was successively extracted in a Soxhlet apparatus with $n$-hexane (HX), chloroform (CF) and methanol (ME) (based on increasing polarity). The volume of each extractive was reduced by using a Buchii rotary evaporator at low temperature and pressure.

An aliquot $(1.0 \mathrm{gm})$ of the concentrated chloroform extract was subjected to column chromatography for fractionation over silica gel (Kieselgel 60, mesh 70-230). PTLC of a column fraction with $n$-hexane - ethyl acetate (5:1) provided $\beta$-sitosterol (1) as colorless amorphous mass.

The extractives of $A$. compressus were subjected to screenings for antibacterial activity and cytotoxicity against brine shrimp nauplii following the method developed by Bauer et al. (1966) and Meyer et al. (1982), respectively. The antioxidant potential of the extracts was

Correspondence to: A. F. M. Mustafizur Rahman, Tel: (+ 880-2)-9661900-73, Extn.-7405; E-mail: banglatapu@ yahoo.com 
also assessed by evaluating the scavenging activities of the stable 1,1-diphenyl-2-picrylhydrazyl (DPPH) free radical (Brand-Williams et al., 1995).

The present investigation showed that fractions F-1 and F-2 obtained from the chloroform extract have mild growth inhibitory activity against almost all the bacteria and fungi with average zone of inhibition of $8-10 \mathrm{~mm}$, whereas the crude HX, CF and ME extracts did not show any antimicrobial activity at the tested concentration.

It was found from the result of the brine shrimp lethality test (Table 2) that the crude extracts (HX, CF and
ME) of A. compressus exhibited toxicity towards brine shrimp. There was no mortality in the negative control group indicating the validity of the test. $\mathrm{LC}_{50}$ obtained from the best-fit line slope were $0.3229,1.88,2.11$ and $2.50 \mu \mathrm{g} / \mathrm{ml}$ for vincristine sulphate (Std.), HX, CF and ME extracts, respectively. In comparison to positive control (vincristine sulphate), the $n$-hexane, chloroform and methanol extracts were found to be highly cytotoxic. This indicates that the plant might have antitumour or pesticidal compounds.

Table 1. Antimicrobial activity of $A$. compressus.

\begin{tabular}{lccc}
\hline \multirow{2}{*}{ Test microorganisms } & \multicolumn{3}{c}{ Diameter of zone of inhibition $(\mathrm{mm})$} \\
\cline { 2 - 4 } & F-1 & F-2 & Kanamycin \\
\hline Bacillus cereus & 9 & 8 & 26 \\
B. megaterium & 10 & 8 & 24 \\
B. subtilis & 9 & 8 & 25 \\
Escherichia coli & - & - & 25 \\
Pseudomonas aeruginosa & 7 & 7 & 23 \\
Salmonella Paratyphi & 9 & 8 & 25 \\
S. Typhi & 8 & 9 & 25 \\
Sarcina lutea & 8 & 7 & 22 \\
Staphylococcus aureus & - & - & 23 \\
Shigella boydii & 7 & 7 & 23 \\
Sh. dysenteriae & 7 & 7 & 25 \\
Vibrio mimicus & 8 & 8 & 24 \\
V. parahaemolyticus & 8 & 7 & 25 \\
Aspergillus niger & 8 & 8 & 25 \\
Candida albicans & 8 & 7 & 25 \\
Saccharomyces cerevisiae & 7 & 7 & 23 \\
\hline
\end{tabular}

A diameter less than $8 \mathrm{~mm}$ was considered as inactive.

Table 2. Brine shrimp lethality of the crude extracts of $A$. compressus.

\begin{tabular}{cccc}
\hline Sample & $\mathrm{LC}_{50}(\mu \mathrm{g} / \mathrm{ml})$ & Regression equation & $\mathrm{R}^{2}$ \\
\hline $\mathrm{VS}$ & 0.32 & $\mathrm{y}=29.797 \mathrm{x}+64.624$ & 0.927 \\
$\mathrm{HX}$ & 1.88 & $\mathrm{y}=23.233 \mathrm{x}+43.619$ & 0.915 \\
$\mathrm{CF}$ & 2.11 & $\mathrm{y}=25.961 \mathrm{x}+41.537$ & 0.961 \\
$\mathrm{ME}$ & 2.50 & $\mathrm{y}=24.748 \mathrm{x}+40.140$ & 0.983 \\
\hline
\end{tabular}

VS: vincristine sulphate (Std.).

The crude extracts (HX, CF and ME) of $A$. compressus were also subjected to free radical scavenging activity to evaluate the antioxidant potential by using tert-butyl-1hydroxytoluene (TBHT) and ascorbic acid as reference standards. The results are summarized in Table-3. It has been observed that the $\mathrm{CF}$ extract showed the highest antioxidant activity with $\mathrm{IC}_{50}$ value of $48.0 \mu \mathrm{g} / \mathrm{ml}$ and it is clearly evident that the $\mathrm{CF}$ extract might play important roles in preventing free radical induced-diseases. On the other hand, both $\mathrm{HE}$ and ME extracts showed mild antioxidant activity, with $\mathrm{IC}_{50}$ values of $292.0 \mu \mathrm{g} / \mathrm{ml}$ and $188.0 \mu \mathrm{g} / \mathrm{ml}$, respectively. 
From the above investigations it has been found that different solvent extracts of $A$. compressus have significant cytotoxic activity and the partially purified fractions (F-1 and F-2) obtained from the chloroform extact have mild antimicrobial activity. The high lethality to brine shrimp nauplii by all extracts is a clear indication of the presence of antitumour or pesticidal compounds. In the present study, we have isolated $\beta$-sitosterol and detailed chemical investigation of this plant is further required to isolate the molecules that are responsible for cytotoxicity, antimicrobial and antioxidant activities.

Table 3. $\mathrm{IC}_{50}$ values of standard and test samples of $A$. compressus.

\begin{tabular}{cc}
\hline Sample & $\mathrm{IC}_{50}(\mu \mathrm{g} / \mathrm{ml})$ \\
\hline TBHT $($ Standard $)$ & $27.5 \pm 0.54$ \\
Ascorbic acid & $5.8 \pm 0.21$ \\
HX & $292.0 \pm 2.03$ \\
CF & $48.0 \pm 0.96$ \\
ME & $140.0 \pm 1.03$ \\
\hline
\end{tabular}

The values of $\mathrm{IC}_{50}$ are expressed as mean $\pm \mathrm{SD}(\mathrm{n}=3)$. TBHT: tert-butyl-1-hydroxytoluene.

\section{Acknowledgement}

The authors would like to thank Dr. Hossain Sohrab, Senior Scientific Officer, Analytical Research Division, BCSIR, Dhaka-1205 for his kind cooperation for recording NMR spectrum.

\section{References}

Bauer, A.W., Kibry, W.M.M., Sheris, J.C. and Truck, M. 1966. Antibiotic susceptibility testing by a standard single disc method. Am. J. Clin. Pathol. 45, 493-496.
Brand-Williams, W., Cuvelier, M.E. and Berset, C. 1995. Use of free radical method to evaluate antioxidant activity. Lebensm. Wiss. Technol. 28, 25-30.

Busia, K. 2007. Herbal pharmacopoeia: Science and Technology Policy Research Institute Council for Scientific and Industrial Research, Quality PC Limited, Accra North, Ghana. pp. 30-133.

Gohl, B. 1975. Tropical feeds information summeries and nutritive values. Food and Agricultural Organization (FAO); Agricultural Studies No. 96, United Nations, Rome, Italy, pp. 148-149.

Ibeh, B.O. and Ezeja, M. 2011. Preliminary study of antidiabetic activity of the methanolic leaf extract of Axonopus compressus (P. Beauv) in alloxan-induced diabetic rats. $J$. Ethnopharmacol. 138, 713-716.

Ibeh, B.O., Maxwell, E. and Bitrus, H.J. 2013. Phytochemical compositions and in vitro antioxidant capacity of methanolic leaf extract of Axonopus compressus (P. Beauv.), Euro. J. Med. Plants. 3 (in press).

Lowe, J. 1989. The Flora of Nigeria grasses. Ibadan University Press, Ibadan, Nigeria.

Meyer, B.N., Ferringni, N.R., Puam, J.E., Lacobsen, L.B., Nichols, D.E. and McLaughlin, J.L. 1982. Brine shrimp: a convenient general bioassay for active constituents. Planta Med. 45, 31-32.

Rocha, G.L., Martinelli, D., Correa, A., Tundisi, A.G.A., Lima, F.P. and Kalil, E.B. 1962. Comparative value of grasses for meat production. Bolet. da Inds. Animal. 20, 289-296.

Soladoye, M.O., Adetayo, M.O., Chukwuma, E.C.C. and Adetunji, A.N. 2010. Ethnobotanical survey of plants used in the treatment of haemorrhoids in South-Western Nigeria, J. Adv. Dev. Res. 2, 100-111.

Ukpong, E.G., Udosen, E.D., Asuquo, J.E. and Etim, E.E. 2011. Concentrations of trace metals in Axonopus compressus within an abandoned steel industry environment. J. Emerg. Trends Eng. App. Sci. 2, 972-977. 